\title{
Enfermedad celiaca del adulto
}

\section{Sr. Director:}

Hemos leído con interés el trabajo de Cabral Rodríguez y cols. de su revista (1). La enfermedad celiaca es una enteropatía inmunológicamente mediada que se comporta como una enfermedad genética crónica relacionada con el gluten de la dieta y se presenta de forma clásica como malbasorción (2). Las formas de presentación en edades no pediátricas se consideraban hasta hace poco anecdóticas pero de forma cada vez mayor se han ido definiendo dos presentaciones, pediátrica (la más frecuente) y del adulto (3). La alta importancia de los factores genéticos en la enfermedad se sustenta en la prevalencia de la enfermedad de hasta el $10 \%$ en los familiares de primer grado (4).Se estima que más del $95 \%$ de los pacientes con enfermedad celíaca expresan un alelo heterodímero del complejo mayor de histocompatibilidad (HLA) DQ2 y haplotipos DQ8 (3). Esta asociación de alelos se presenta en el $98 \%$ de los pacientes celíacos del norte de Europa (5) pero se desconoce por que sólo una pequeña parte de la población que son portadores de éstos, padecen la enfermedad. Por eso también la necesidad de realizar screening a los familiares de los diagnosticados, en los que hay que pensar no solo ante la presencia de malabsorción. La prevalencia de la enfermedad en su presentación en el adulto es desde hace un tiempo materia de discusión (6). La existencia de un número cada vez más alto de pacientes con clínica no gastrointestinal o con cuadros subclínicos de malabsorción hizo que se introdujera el concepto de "iceberg" (7) de la enfermedad, considerando la parte "visible" sólo una minoría de la enfermedad real.

Presentamos las características clínicas de 8 pacientes de edades entre 17 y 70 años diagnosticados de enfermedad celíaca y 
sus manifestaciones clínicas (Tabla I). Nuestros datos confirman la presentación clínica mayoritaria en mujeres al igual que el caso expuesto por Cabral Rodríguez y cols. (1), la aparición en algún caso de tetania al igual que el caso descrito y la ausencia de las complicaciones relacionadas con la enfermedad celíaca (ningún caso en nuestros pacientes) a pesar de los estadios histológicos con importante deterioro vellositario en nuestro resultados, así como el excelente comportamiento de la enfermedad con las medidas dietéticas (sólo una paciente en nuestro estudio presentó reingresos repetidos por transgresiones dietética repetidas).

En la enfermedad celíaca su aumento cada vez más frecuente tiene mucho que ver con la mejoría en los test diagnósticos que contribuyen a mostrar que la enfermedad se expresa de forma similar en adultos y en niños con una gran variedad de síntomas que abarca un gran espectro de sistemas y órganos. Recientemente se ha establecido que a diferencia de lo que se creía clásicamente, la incidencia en EE.UU. es similar a la de la población europea (8) con un rango del 4,5\% de incidencia en los familiares de primer grado a un $0,75 \%$ de incidencia en pacientes no emparentados. También se determina en este estudio como la incidencia en adultos es alta (de los 13140 pacientes estudiados 8631 eran adultos y 220 de los 350 diagnosticados eran adultos). Así mismo se insiste como en nuestro estudio y otro recientes (9) en la presentación subclínica y/o extraintestinal de la enfermedad. En definitiva las evidencias apuntan de forma cada vez más insistente en que la enfermedad se presenta en individuos genéticamente predispuestos, aunque el o los genes que definen esta predisposición todavía se desconocen. Si la mejoría en los test diagnósticos está permitiendo sacar a la luz a pacientes con la enfermedad incluso en ausencia de síntomas clásicos, se considera cada vez más importante la determinación de pruebas genéticas que permitan el diagnóstico. Pero aún más importante es

TABLA I

CARACTERÍSTICAS CLÍNICAS Y ANALIITICAS DE LOS

PACIENTES CON ENFERMEDAD CELIACA DEL ADULTO ESTUDIADOS

\begin{tabular}{|c|c|c|}
\hline \multirow[t]{2}{*}{ Sexo } & Hombre (\%) & Mujer (\%) \\
\hline & $1(12,5)$ & $7(87,5)$ \\
\hline \multicolumn{2}{|c|}{ Presentación clínica } & (Número de casos) $^{1}$ \\
\hline \multicolumn{2}{|c|}{ Astenia } & (8) \\
\hline \multicolumn{2}{|c|}{ Pérdida de peso } & (8) \\
\hline \multicolumn{2}{|c|}{ Diarrea } & (8) \\
\hline \multicolumn{2}{|c|}{ Náusea/vómitos } & (7) \\
\hline \multicolumn{2}{|c|}{ Anorexia } & (2) \\
\hline \multicolumn{2}{|c|}{ Calambres } & (2) \\
\hline \multicolumn{2}{|c|}{ Anemia ferropénica } & (2) \\
\hline \multicolumn{2}{|c|}{ Tetania (hipocalcemia) } & (1) \\
\hline \multicolumn{2}{|c|}{ Esterilidad } & (1) \\
\hline
\end{tabular}

Elevación en niveles de anticuerpos

$\begin{array}{ll}\text { Antigliadina } & 7 \\ \text { Antiendomisio } & 7\end{array}$

Biopsia intestinal (atrofia vellositaria, calsificación Mettayer)

$\begin{array}{ll}\text { Grado I: } & 1 \text { paciente } \\ \text { Grado II: } & 2 \text { pacientes } \\ \text { Grado III: } & 3 \text { pacientes } \\ \text { Grado IV: } & 1 \text { paciente } \\ \text { Grado V: } & 1 \text { paciente }\end{array}$

${ }^{\top}$ Varios pacientes presentaron dos o mas síntomas/signos. seleccionar a los pacientes en los que debe confirmarse la enfermedad. La sospecha clínica ha de ampliarse a un espectro cada vez mayor de manifestaciones, pero se comienza a aplicar lo que Sir William Osler ya utilizó para otras patologías, y tener a la enfermedad celíaca como una nueva "gran simuladora" (10). Para ello es necesario olvidar la antigua asociación de la enfermedad como exclusiva de la edad pediátrica y concluir que se trata de una enfermedad sin límites de edad en su manifestación inicial. De hecho la presencia de síntomas a veces inespecíficos e inexplicables debería hacer pensar en ésta.

\section{Villamil Cajoto, A. Capparrini Escondrillas', M. J. Villa-} cián Vicedo ${ }^{2}$, E. Otero Antón, A. González Quintela

Servicios de Medicina Interna, ${ }^{1}$ Anatomía Patológica y ${ }^{2}$ Pediatría. Hospital Clínico Universitario. Santiago de Compostela. A Coruña

1. Cabral Rodríguez R, Arrieta Blanco FJ, Vicente sánchez F, Cordobés Martín FJ, Moreno caballero B. Enfermedad celíaca oligisintomática del adulto. An Med Interna (Madrid) 2004; 21: 599-601.

2. Troncote P, Greco L, Auricchio S. Gluten-sensitive enteropathy. Pediatr Clin North Am 1996; 42: 355-73.

3. Farrel RJ, Kelly CP. Celiac sprue N Engl J Med 2002; 346: 180-8.

4. Mac Donald WC, Dobbins WO 3rd, Rubin CE. Studies on the familial nature of celiac sprue using biposy of the small intestine. N Engl J Med 1965; 272: 448-56.

5. Sollid LM, Markussen G, Ek J, Gjerde H, Vartdal F, Throsby E. Evidence for a primary asociation of coeliac disease to a particular HLA DQ a/b heterodimer. J Exp Med 1989; 169: 345-50.

6. Mann JG, Brown WR, Kern F Jr. The subtle and variable clinical expressions of gluten-induced enteropathy (adult celiac disease, nontropical sprue). An Analysis of twenty-one consecutive cases. Am J Med 1970; 48: 357-66.

7. Catassi C, Ratsch IM, Fabiani E, Rossini M, Bordicchia F, Candela F, et al. Coeliac disease en the year 2000: exploring the iceberg. Lancet 1994;343:200-203.

8. Fasano A, Berti I, Gerarduzzi T, Not T, Colletti RB, Drago S, Elitsur Y, et al. Prevalence of celiac disease in At-Risk and Non-at-Risk Groups in the United States. A Large Multicenter Study. Arch Intern Med 2003; 163: 286-292.

9. Maki M, Mustalahti K, Kokkonen J, Kulmala P, Haapalahti M, Karttunen T, et al. Prevalence of celiac disease among children in Finland. N Eng J Med 2003; 348: 2517-2524.

10. Duggan JM. Coeliac Disease: the great imitator. Med J Aust 2004; 180: 524-526. 